\title{
Sonication improves the efficiency, efficacy and safety of phytolith extraction
}

Umberto Lombardo ${ }^{1}$; Javier Ruiz-Pérez ${ }^{1}$; Marco Madella ${ }^{1}$

${ }^{1}$ CaSEs - Complexity and Socio-Ecological Dynamics Research Group, Departament of Humanities, Pompeu Fabra University. Ramon Trias Fargas 25-27, Mercè Rodoreda Building, 08005 Barcelona, Spain

Corresponding author: Umberto Lombardo (umberto.lombardo@upf.edu)

\begin{abstract}
Phytolith analysis is increasingly used in archaeological and paleoecological research, yet the methods used to extract phytoliths from some types of sediments are still not completely satisfactory. This paper reports on the effect of adding sonication to protocols frequently used for phytolith extraction. We compare two common methods of phytolith extraction, both with and without part of the process being carried out in an ultrasound bath. Results show that sonication permits the destruction of soil micro aggregates and, in doing so, improves the removal of both soil organic matter and clay. Adding sonication to commonly used protocols for phytolith extraction is inexpensive and reduces the processing time and the need to use dangerous products, even with the samples that are most difficult to treat. Sonication increases the purity of the extracted phytoliths as well as augmenting the quantity of recovered phytoliths.
\end{abstract}

\section{Keywords}

Ultrasound, microfossil, biogenic silica, organic matter, clay

\section{Introduction}

In recent years, the dramatic increase of archaeological and paleoecological reconstructions that rely on the analysis of phytoliths (Hart, 2016) attests the great potential of phytoliths as a proxy for studying such things as past use and domestication of plants (e.g. Iriarte et al., 2010; Madella et al., 
2014; Piperno, 2009; Piperno and Stothert, 2003) and for the reconstruction of changes in vegetation cover (e.g. Barboni et al., 1999; Bremond et al., 2005; Strömberg, 2004; Strömberg and Mclnerney, 2011). Phytoliths are discrete bodies of biogenic silica produced within plant tissues, which have taxonomic significance and are produced in large quantities by many plant types (Ball et al., 2016; Piperno, 2006). After plant decay, phytoliths are accumulated in the soil, where the amount of biogenic silica stored as phytoliths can be as much as 1000 times the silica found in the living biomass (Conley, 2002). Phytoliths are the most durable of plant fossils known to science (Blinnikov et al., 2002; McInerney et al., 2011).

Phytolith analysis consists in identifying and counting phytoliths mounted on glass slides using transmitted light microscopy. It is a time consuming activity which can be very challenging and biased if the extraction of phytoliths is unsatisfactory. As noted in Madella et al. (1998), an extraction is successful if it permits: i) the recovery of a representative assemblage of the biogenic silica contained in the original sediment; ii) the concentration of the silica fraction; and iii) can be carried out economically, safely and quickly. The process of extracting phytoliths from sediments consists of four steps: the dissolution of carbonates; the oxidation of organic matter (OM); the removal of clay; and the gravimetric separation of biogenic silica from the mineral fraction. The most challenging of these four steps are the oxidation of organic matter and the removal of clay. (Boyd et al., 1998; Lentfer and Boyd, 1998; Parr, 2002; Zhao and Pearsall, 1998). The most common procedure for the oxidation of OM is treating the sediments with $30 \% \mathrm{H}_{2} \mathrm{O}_{2}$ in a hot water bath (Lentfer and Boyd, 1998; Madella et al., 1998; Pearsall, 2015; Piperno, 2006). This procedure has the advantage of being relatively easy, safe and inexpensive. It has been used to extract phytoliths in studies of the oxygen isotope composition of phytoliths (Alexandre et al., 2012) and for radiocarbon dating (Madella et al., 2014). Radiocarbon dating and other analyses based on $\mathrm{C}$ isotopes are possible because between $0.2 \%$ and $2 \%$ of phytolith weight is OM (Piperno, 2006). Most of the phytolith OM is mixed with silica (Gallagher et al., 2015) and therefore is preserved within the phytoliths and can be used for the 
analysis of stable $\mathrm{C}$ isotope only if the extracted phytoliths are pure, i.e. soil organic matter (SOM) has been completely removed (Piperno, 2016; Santos et al., 2012). In some cases, $\mathrm{H}_{2} \mathrm{O}_{2}$ alone is not sufficient to oxidize all the OM; e.g. it has been shown that between $10 \%$ and $15 \%$ of SOM in cultivated soil is resistant to $\mathrm{H}_{2} \mathrm{O}_{2}$ oxidation (Leifeld and Kögel-Knabner, 2001; Plante et al., 2004). The reasons for this are not completely understood, but it seems that the formation of aggregates $(<250 \mu \mathrm{m})$ of clay and OM is a key factor in the stabilization of SOM (Six et al., 2002; Theng et al., 1992), and, hence, in the accumulation of $\mathrm{H}_{2} \mathrm{O}_{2}$ resistant SOM (Leifeld and Kögel-Knabner, 2001; Plante et al., 2004). If not destroyed, these aggregates are extracted together with the phytoliths by gravimetric separation with heavy liquid (step 4). The quantity of clay aggregates may well be greater than the weight of the extracted phytoliths (Pansu and Gautheyrou, 2006). Therefore, if they are not completey destroyed, this reduces significantly the accuracy with which the concentration of phytoliths in the original sediments can be estimated. Current methods that improve the oxidation of OM include: pressurized microwave digestion (Parr, 2002); the use of strong acids (Corbineau et al., 2013; Pearsall, 2015; Piperno, 2016); burning the samples until all the organic matter is reduced to ash (Powers and Gilbertson, 1987); the application of acetolysis (Costa et al., 2016); or the use of a combination of strong acids and burning (Corbineau et al., 2013; Mclnerney et al., 2011). However, all these methods have drawbacks: the addition of further reactions and the use of strong acids make the process more complex, expensive, time consuming and dangerous; burning is not reliable if samples contain clay (Lentfer and Boyd, 1998); pressurized microwave digestion only allows the processing of very small samples (Parr, 2002), 0.25 grams instead of the usual 5-10 grams. Moreover, some of these methods (Corbineau et al., 2013; Costa et al., 2016) have only been tested for the extraction of phytoliths from modern plants and their effectiveness in destroying soil clay aggregates is still unknown.

In this article, we propose using ultrasonic vibration (or sonication) to improve the efficiency, efficacy and safety of phytolith extraction from sediments. As sonication could destroy articulated phytoliths (Katz et al., 2010), we do not recommend its use in those cases where they need to be preserved. 
Sonication is the process by which, through the application of ultrasound to a liquid, micro-bubbles form, grow and collapse causing extremely high temperatures and pressure during microseconds (Suslick, 1990). Water sonication has been used widely to destroy soil aggregates and improve the dispersion of the sediments since the mid 60's (Edwards and Bremner, 1967). With the exception of Katz et al. (2010), we are not aware of any protocol used for the extraction of phytoliths from sediments that includes sonication. Sonication can act in two different ways: on the one hand, it increases the dispersion of sediments by destroying clay aggregates (Pansu and Gautheyrou, 2006); on the other hand, it produces $\mathrm{H}^{+}$and $\mathrm{OH}^{-}$, which can combine to form either $\mathrm{H}_{2}$ or $\mathrm{H}_{2} \mathrm{O}_{2}$ (Henglein, 1987). Sonication has been shown to enhance the activity of $\mathrm{H}_{2} \mathrm{O}_{2}$, improving the oxidation of humic substances (Chemat et al., 2001). An ultrasonic bath is a relatively inexpensive piece of equipment and is part of any phytolith lab, as it is used regularly to clean samples of modern plants before processing them for reference collections or to extract phytoliths and starch residues from artifacts (Pearsall, 2015). Here, commonly used methods of phytolith extraction carried out without an ultrasound bath are compared with the same methods plus sonication. We discuss how sonication can improve the extraction of phytoliths for optical microscopy and for isotopic studies and suggest how to incorporate sonication in currently used protocols.

\section{Material and methods}

The samples used for the experiment come from early and mid-Holocene neotropical shell middens (Lombardo et al., 2013). We chose samples from these sites because, being old and rich in clay, organic matter and calcium, they contain a great amount of soil micro aggregates (Six et al., 2004). With these samples, standard methods of phytolith extraction are likely to give poor results and we can test whether the use of sonication provides better results. Eight samples were used, approximately 80 grams each, taken from three different shell middens at different depths (See Table 1). Each of these samples was divided into two samples of approximately 40 grams each and processed following the "phase 1" steps (table 2). Each sample was divided into four sub-samples and each sub-sample was processed following a different protocol. Two of these four protocols did 
not include the use of sonication: Standard Oven (SO) and Standard Light (SL). The other two protocols, which include the use of sonication, are Ultrasound Oven (UO) and Ultrasound Light (UL). The SO protocol follows the burning method delineated in Lentfer and Boyd (1998), where organic matter is removed by burning the samples in a furnace after they have been shaken in $5 \%$ sodium hexametaphosphate solution and cleared from carbonates with $10 \% \mathrm{HCl}$. In the SL protocol, based on Madella et al. (1998), samples are processed with sodium hexametaphosphate and $\mathrm{HCl}$ as in the SO protocol, but organic matter is oxidized using $30 \% \mathrm{H}_{2} \mathrm{O}_{2}$. The $\mathrm{UO}$ and the $\mathrm{UL}$ protocols include the same steps as SO and SL respectively, but several steps are performed in an ultrasound bath: the initial dispersion with sodium hexametaphosphate, the oxidation of organic matter with $30 \% \mathrm{H}_{2} \mathrm{O}_{2}$ and the second dispersion with sodium hexametaphosphate. Samples were sonicated in $50 \mathrm{ml}$ plastic tubes, which were placed inside the ultrasound bath (a 3 liter ultrasound bath can contain up to 16 tubes). The intensity of the ultrasounds inside the ultrasonic bath is not homogeneous, therefore tubes were placed randomly, and their position inside the ultrasound bath was changed for each new step in the sonication process. Each of these four protocols is described in more detail in Table 2.

The workflow was divided into 3 phases (see Table 2) and after each phase samples were dried and weighed to measure the effects of each protocol on removing carbonates, clay and organic matter. Moreover, a portion of the extract was examined under the microscope to better quantify these effects. In order to mount a known quantity of phytoliths on the microscope glass slides, the extract was diluted with a known amount of distilled water (Dw) and $0.5 \mu \mathrm{l}$ of the suspension was placed on the glass slide, dried and mounted with Entellan ${ }^{\circledR}$. Slides were analyzed with an Olympus BX51 transmitted light microscope at 500X, and all the identifiable biogenic silica bodies within a field of view were counted together with clay aggregates (micro and macro, here defined as 5-50 $\mu \mathrm{m}$ and $>50 \mu \mathrm{m}$, respectively), charcoal fragments $(>5 \mu \mathrm{m})$, unidentified opal $(>5 \mu \mathrm{m})$, and mineral quartz $(>5$ $\mu \mathrm{m})$. The number of broken phytoliths was recorded in order to assess to what extent the exposure to prolonged sonication damages the phytoliths. For each slide, a total of 250-300 particles was counted. The total number of extracted phytoliths $\left(T_{e}\right)$ was calculated by multiplying the average 
number of phytoliths for each field of view by the number of field of views in one slide by Dw/0.5 $\mu$ l. In order to compare the different methods, two indexes were defined. A purity index $\mathrm{P}_{\mathrm{i}}$ was defined as $\left(T_{c}-T_{p}\right) / T_{c}$, where $T_{c}$ is the total amount of counted elements (phytoliths plus clay aggregates), and $T_{p}$ is the total amount of phytoliths counted in one slide. A fragmentation index $F_{i}$ was defined as $\left(T_{p^{-}}\right.$ F)/ $T_{p}$, where $F$ is the number of broken phytoliths.

\section{Results and interpretation}

After phase 1 , part of the clay and SOM content had been eliminated by dispersion and the totality of carbonates dissolved with $10 \% \mathrm{HCl}$. The differences in weight between samples that had been shaken and samples dispersed with sonication (Figure 1a) indicate that, in most cases, 20 minutes of sonication were more effective in removing clay and SOM than 24 hours of shaking. Carbonates were removed with $10 \% \mathrm{HCl}$ in the same manner for all the samples; therefore they have had little to no influence on the weight difference shown in Figure 1a. The SOM and clay that were not washed out in phase 1 , were further removed in the second phase. After phase 2 , samples treated with ultrasound weighed far less than the rest (Figure 1b), even though most of these samples had already lost more material during phase 1.

UL outperformed SL in all the samples, with the exception of SM4 0, in which the results of UL and SL are almost equivalent. The same is true for the oven samples, with UO obtaining better results than $\mathrm{SO}$ in all the samples but one. The difference in the amount of material removed between ultrasound and the standard methods is, in some cases, quite substantial. In the case of the samples from SM1, the UL method removed up to three times more material than the SL method. Interestingly, the difference between SL and UL is smaller in the case of the modern samples (SM3 0 and SM4 0 ) and much larger in the case of the sub-surface (older) samples (Figure 1b). However, the combined results from phases 1 and 2 (Figure 1c) show that sonication improved the removal of clay and organic matter for all the samples. Moreover, several samples show a clear inverse relation between 
the amount of material removed in phases 1 and 2 (Figure 1c) and the amount of material extracted with flotation (Figure 1d), indicating that a fraction of the clay aggregates that was not destroyed through SO and SL procedures had floated together with the phytoliths and ended up in the extract. This is further confirmed by looking at the Purity Index $\left(P_{i}\right)$ (Figure 2a). The $P_{i}$ shows that the material extracted using the UL method consists almost exclusively of phytoliths, whereas up to $30 \%$ of the material extracted using the SL method may consist of soil aggregates. $P_{\mathrm{i}}$ is consistent with the amount of phytoliths per gram of extract (Figure $2 \mathrm{~b}$ ), although the comparison between SO and SL is not easy to interpret. It seems that when performing the SO procedure most of the clay hardened in the oven forming large aggregates, containing part of the mineral fraction. These were discharged after the heavy liquid flotation. In contrast, in the case of $\mathrm{SL}$, the clay was still in the form of micro aggregates and part of it was extracted together with the phytoliths. While the extract was drying, the clay hardened and formed new aggregates that consisted almost exclusively of clay and phytoliths. These phytoliths could not be counted because they were not visible under the microscope, but we did count the large clay aggregates. On average, 0.3 macro aggregates $(>50 \mu \mathrm{m})$ per field view were counted on SL slides, while only 0.1 were counted on SO slides. The Fragmentation Index $\left(\mathrm{F}_{\mathrm{i}}\right)$ shows that phytoliths can be exposed to sonication for long and continued periods without any damage (Figure 2c).

\section{Discussion}

The effects of sonication in the process of phytolith extraction can be assessed at each phase (Table 2). Phase 1 clearly shows that the first advantage of using sonication is saving time. During the first washing of the samples with sodium hexametaphosphate, 20 minutes of sonication offered similar or better results than 24 hours of shaking (Figure 1a). With respect to phase 2 , the removal of SOM and clay, we did not measure the total amount of organic matter left in the extract, therefore we cannot be certain that the reaction with $\mathrm{H}_{2} \mathrm{O}_{2}$ in the ultrasonic bath was more efficient than outside the 
ultrasonic bath. However, if we take into account that most of the SOM recalcitrant to $\mathrm{H}_{2} \mathrm{O}_{2}$ is enclosed with clay in micro aggregates (Leifeld and Kögel-Knabner, 2001; Plante et al., 2004), then, a more efficient removal of SOM should be accompanied by an increase in the amount of clay that is suspended in the supernatant. This is exactly what we observed after phase 2 , where sonicated samples lost far more clay than non-sonicated ones (Figure 1b). This is also observed in the analysis of the material under the microscope, which shows a higher Purity Index $\left(P_{i}\right)$ for sonicated samples. $P_{i}$ is very close to 1 in the case of UL samples, which suggests that the extract is almost completely made of pure silica; hence, the SOM has been almost completely removed. Interestingly, Figure 1b shows that the difference between SL and UL depends on the samples, the difference being greater for the sub-surface (older) samples. This is consistent with the assumption that the $\mathrm{H}_{2} \mathrm{O}_{2}$ recalcitrant SOM is mostly found in clay micro aggregates, as these are more likely to be found in old and carbonate rich soils than in the topsoil (Six et al., 2004).

Following the definition of a successful extraction of phytoliths put forward by Madella et al. (1998), our data shows that sonication clearly improves several aspects of the extraction of phytoliths from sediments. We did not test whether sonication improved the representativeness of the biogenic silica contained in the original sediment, as we did not identify the extracted phytoliths. However, it can be argued that, at least for SL, which is one of the protocols most commonly used to extract phytoliths from sediments, the smallest phytoliths were more likely to be embedded in the clay aggregates that formed during the drying of the extract, as the smaller a phytolith is, the more likely it is to be deposited in the upper part of the precipitate, together with the clay. It is also interesting to note that $\mathrm{UO}$ has a higher $\mathrm{P}_{\mathrm{i}}$ than $\mathrm{SO}$, as well as more phytoliths per gram of extract. This difference is probably due to the fact that while the SO samples were vortexed with sodium hexametaphosphate, which is unlikely to break the clay aggregates that formed in the oven, the UO samples were repeatedly exposed to $10 \mathrm{~min}$ of ultrasound, which destroyed those clay aggregates, releasing the phytoliths that were trapped in them. This would explain why, even after 10 sodium hexametaphosphate/ultrasound cycles, the UO supernatant was still not clear. At each new 
sonication, a new fraction of the clay aggregates was destroyed, the supernatant had more suspended clay and more phytoliths were released. In theory, repeated sodium hexametaphosphate/ultrasound cycles should result in a completely clear supernatant, producing high quality extracts, but we do not propose this procedure as it would be an extremely time consuming process. Instead, we recommend the UL procedure because, as shown in Figure $2 a-b$, this method increases the concentration of the silica fraction in the extract, producing almost pure extracts.

We think that adding sonication steps to the protocols currently used to extract phytoliths for isotopic studies and radiocarbon age would greatly reduce the chances that the extract is contaminated with SOM. However, we are aware that sonication might destroy silica skeletons; thus, we suggest it should not be used in those cases where articulated phytoliths need to be preserved. We propose that, in addition to using sonication before the flotation with SPT (Katz et al., 2010), sonication steps can also be added during sodium hexametaphosphate treatments and during $\mathrm{H}_{2} \mathrm{O}_{2}$ oxidation of OM, as we did in this experiment (UL method). Also, our results show that the quality of phytoliths extracted can be greatly improved without having to use dangerous acids or expensive equipment (e.g. the model of ultrasound bath we used in this study costs less than 100 US\$). We are currently working on further laboratory experiments to test whether sonication can help overcome some of the problems associated with obtaining reliable radiocarbon ages from phytoliths (Piperno, 2016; Santos et al., 2012).

\section{Conclusions}

This study shows that the standard protocols for extracting fossil phytoliths from sediments can be improved by carrying out some steps of these protocols in an ultrasonic bath. Sonication breaks down soil micro and macro aggregates, increasing the elimination of clay and soil organic matter from the mineral fraction. This results in increased quantity and quality: more phytoliths are 
extracted and they are more pure. Sonication is an easy to use, inexpensive and safe tool even for those sediments that are most difficult to treat.

\section{Acknowledgements.}

The present study has been funded by the Swiss National Science Foundation (SNSF) grant no P300P2158459/1. CaSEs is a recognised and funded Research Group of the Generalitat de Catalunya (2014 SGR 1417). We would like to thank Elisa Canal-Beeby and the two anonymous reviewers who helped improve earlier versions of the manuscript.

\section{References}

Alexandre, A., Crespin, J., Sylvestre, F., Sonzogni, C., Hilbert, D.W., 2012. The oxygen isotopic composition of phytolith assemblages from tropical rainforest soil tops (Queensland, Australia): validation of a new paleoenvironmental tool. Clim. Past 8, 307-324.

Ball, T., Chandler-Ezell, K., Dickau, R., Duncan, N., Hart, T.C., Iriarte, J., Lentfer, C., Logan, A., Lu, H., Madella, M., Pearsall, D.M., Piperno, D.R., Rosen, A.M., Vrydaghs, L., Weisskopf, A., Zhang, J., 2016. Phytoliths as a tool for investigations of agricultural origins and dispersals around the world. Journal of Archaeological Science 68, 32-45.

Barboni, D., Bonnefille, R., Alexandre, A., Meunier, J.D., 1999. Phytoliths as paleoenvironmental indicators, West Side Middle Awash Valley, Ethiopia. Palaeogeography, Palaeoclimatology, Palaeoecology 152, 87-100.

Blinnikov, M., Busacca, A., Whitlock, C., 2002. Reconstruction of the late Pleistocene grassland of the Columbia basin, Washington, USA, based on phytolith records in loess. Palaeogeography, Palaeoclimatology, Palaeoecology 177, 77-101.

Boyd, W.E., Lentfer, C.J., Torrence, R., 1998. Phytolith analysis for a wet tropics environment: Methodological issues and implications for the archaeology of Garua island, West New Britain, Papua New Guinea. Palynology 22, 213-228. 
Bremond, L., Alexandre, A., Hély, C., Guiot, J., 2005. A phytolith index as a proxy of tree cover density in tropical areas: calibration with Leaf Area Index along a forest-savanna transect in southeastern Cameroon. Global and Planetary Change 45, 277-293.

Chemat, F., Teunissen, P.G.M., Chemat, S., Bartels, P.V., 2001. Sono-oxidation treatment of humic substances in drinking water. Ultrason. Sonochem. 8, 247-250.

Conley, D.J., 2002. Terrestrial ecosystems and the global biogeochemical silica cycle. Global Biogeochemical Cycles 16, 68-61-68-68.

Corbineau, R., Reyerson, P.E., Alexandre, A., Santos, G.M., 2013. Towards producing pure phytolith concentrates from plants that are suitable for carbon isotopic analysis. Review of Palaeobotany and Palynology 197, 179-185.

Costa, F.G.C.M.d., Souza, P.C.T., Klein, D.E., Bove, C.P., 2016. Application of acetolysis in phytoliths extraction. Review of Palaeobotany and Palynology 228, 93-97.

Edwards, A.P., Bremner, J.M., 1967. Dispersion of soil particles by sonic vibration. Journal of Soil Science 18, 47-63.

Gallagher, K.L., Alfonso-Garcia, A., Sanchez, J., Potma, E.O., Santos, G.M., 2015. Plant growth conditions alter phytolith carbon. Frontiers in Plant Science 6.

Hart, T.C., 2016. Issues and directions in phytolith analysis. Journal of Archaeological Science 68, 2431. Henglein, A., 1987. Sonochemistry: Historical developments and modern aspects. Ultrasonics 25, 616. Iriarte, J., Glaser, B., Watling, J., Wainwright, A., Birk, J.J., Renard, D., Rostain, S., McKey, D., 2010. Late Holocene Neotropical agricultural landscapes: phytolith and stable carbon isotope analysis of raised fields from French Guianan coastal savannahs. Journal of Archaeological Science 37, 29842994.

Katz, O., Cabanes, D., Weiner, S., Maeir, A.M., Boaretto, E., Shahack-Gross, R., 2010. Rapid phytolith extraction for analysis of phytolith concentrations and assemblages during an excavation: an application at Tell es-Safi/Gath, Israel. Journal of Archaeological Science 37, 1557-1563. 
Leifeld, J., Kögel-Knabner, I., 2001. Organic carbon and nitrogen in fine soil fractions after treatment with hydrogen peroxide. Soil Biology and Biochemistry 33, 2155-2158.

Lentfer, C.J., Boyd, W.E., 1998. A Comparison of Three Methods for the Extraction of Phytoliths from Sediments. Journal of Archaeological Science 25, 1159-1183.

Lombardo, U., Szabo, K., Capriles, J.M., May, J.-H., Amelung, W., Hutterer, R., Lehndorff, E., Plotzki, A., Veit, H., 2013. Early and Middle Holocene Hunter-Gatherer Occupations in Western Amazonia: The Hidden Shell Middens. PLoS ONE 8, e72746.

Madella, M., García-Granero, J.J., Out, W.A., Ryan, P., Usai, D., 2014. Microbotanical Evidence of Domestic Cereals in Africa 7000 Years Ago. PLoS ONE 9, e110177.

Madella, M., Powers-Jones, A.H., Jones, M.K., 1998. A Simple Method of Extraction of Opal Phytoliths from Sediments Using a Non-Toxic Heavy Liquid. Journal of Archaeological Science 25, 801-803.

McInerney, F.A., Strömberg, C.A.E., White, J.W.C., 2011. The Neogene transition from C3 to C4 grasslands in North America: stable carbon isotope ratios of fossil phytoliths. Paleobiology 37, 23-49. Pansu, M., Gautheyrou, J., 2006. Handbook of soil analysis. Heidelberg: Springer-Verlag. Parr, J.F., 2002. A comparison of heavy liquid floatation and microwave digestion techniques for the extraction of fossil phytoliths from sediments. Review of Palaeobotany and Palynology 120, 315-336. Pearsall, D.M., 2015. Paleoethnobotany: a handbook of procedures, Third edition. Walnut Creek, California, US: Left Coast Press.

Piperno, D.R., 2006. Phytoliths. Oxford, UK: AltaMira Press.

Piperno, D.R., 2009. Identifying crop plants with phytoliths (and starch grains) in Central and South America: A review and an update of the evidence. Quaternary International 193, 146-159.

Piperno, D.R., 2016. Phytolith radiocarbon dating in archaeological and paleoecological research: a case study of phytoliths from modern Neotropical plants and a review of the previous dating evidence. Journal of Archaeological Science 68, 54-61.

Piperno, D.R., Stothert, K.E., 2003. Phytolith Evidence for Early Holocene Cucurbita Domestication in Southwest Ecuador. Science 299, 1054-1057. 
Plante, A.F., Chenu, C., Balabane, M., Mariotti, A., Righi, D., 2004. Peroxide oxidation of clayassociated organic matter in a cultivation chronosequence. European Journal of Soil Science 55, 471478.

Powers, A.H., Gilbertson, D.D., 1987. A simple preparation technique for the study of opal phytoliths from archaeological and quaternary sediments. Journal of Archaeological Science 14, 529-535. Santos, G.M., Alexandre, A., Southon, J.R., Treseder, K.K., Corbineau, R., Reyerson, P.E., 2012. Possible source of ancient carbon in phytolith concentrates from harvested grasses. Biogeosciences 9, 1873-1884.

Six, J., Bossuyt, H., Degryze, S., Denef, K., 2004. A history of research on the link between (micro)aggregates, soil biota, and soil organic matter dynamics. Soil and Tillage Research 79, 7-31. Six, J., Conant, R.T., Paul, E.A., Paustian, K., 2002. Stabilization mechanisms of soil organic matter: Implications for C-saturation of soils. Plant and Soil 241, 155-176.

Strömberg, C.A.E., 2004. Using phytolith assemblages to reconstruct the origin and spread of grassdominated habitats in the great plains of North America during the late Eocene to early Miocene. Palaeogeography, Palaeoclimatology, Palaeoecology 207, 239-275.

Strömberg, C.A.E., Mclnerney, F.A., 2011. The Neogene transition from C3 to C4 grasslands in North America: assemblage analysis of fossil phytoliths. Paleobiology 37, 50-71.

Suslick, K.S., 1990. Sonochemistry. Science 247, 1439-1445.

Theng, B.K.G., Tate, K.R., Becker-Heidmann, P., 1992. Towards Establishing the Age, Location, and Identity of the Inert Soil Organic Matter of a Spodosol. Zeitschrift für Pflanzenernährung und Bodenkunde 155, 181-184.

Zhao, Z., Pearsall, D.M., 1998. Experiments for Improving Phytolith Extraction from Soils. Journal of Archaeological Science 25, 587-598.

\section{Table Captions}

Table 1 Site and location of the samples 
Table 2 Phytolith extraction methods compared in this study. *In the case of the UO samples, the supernatant was never completely clear; we stopped removing the clay after 10 sodium hexametaphosphate cycles.

\section{Figure Captions}

Figure 1 Changes in the weight of the samples processed under the four protocols at different stages of the extraction process (see Table 2).

Figure 2 a) Purity Index, $P_{i}$; b) Millions of Phytoliths per gram of extract; c) Fragmentation Index, $F_{i}$ 

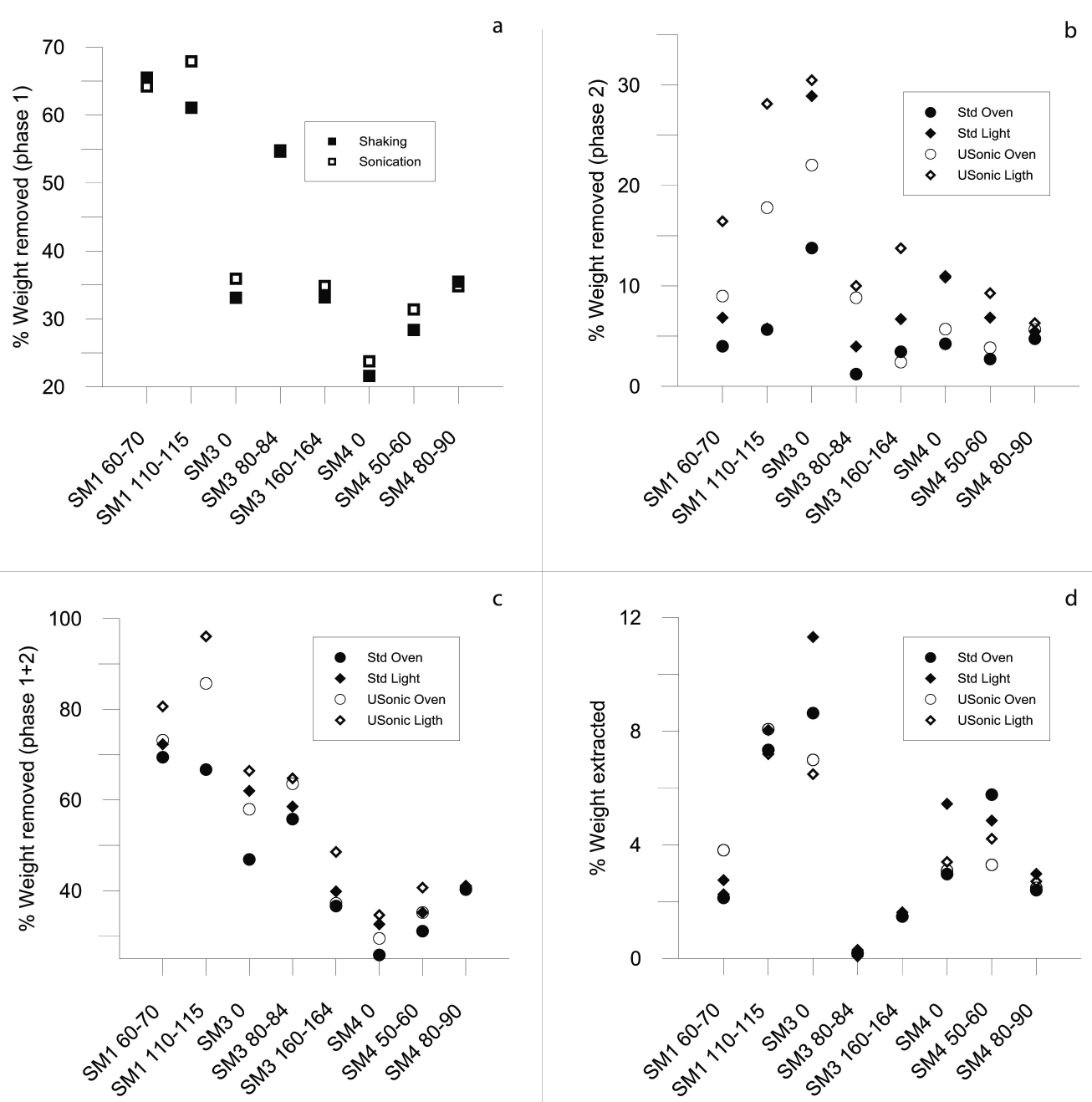


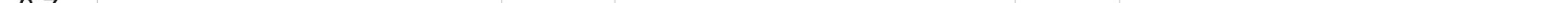




\begin{tabular}{|l|l|l|}
\hline Site & Coordinates of the site & Depth of the sample \\
\hline SM1 & $\begin{array}{l}14^{\circ} 57.781^{\prime} \mathrm{S} \\
64^{\circ} 38.501^{\prime} \mathrm{O}\end{array}$ & $60-70 \mathrm{~cm}$ \\
\hline SM1 & & $110-115 \mathrm{~cm}$ \\
\hline SM3 & $\begin{array}{l}14^{\circ} 51.390^{\prime} \mathrm{S} \\
64^{\circ} 42.186^{\prime} \mathrm{O}\end{array}$ & Surface \\
\hline SM3 & & $80-84 \mathrm{~cm}$ \\
\hline SM3 & & $160-164 \mathrm{~cm}$ \\
\hline SM4 & $\begin{array}{l}14^{\circ} 25.197^{\prime} \mathrm{S} \\
64^{\circ} 45.418^{\prime} \mathrm{O}\end{array}$ & Surface \\
\hline SM4 & & $50-60 \mathrm{~cm}$ \\
\hline SM4 & & $80-90 \mathrm{~cm}$ \\
\hline
\end{tabular}




\begin{tabular}{|c|c|c|c|c|c|}
\hline Phase 1 & & SO & SL & UO & UL \\
\hline \multirow[t]{2}{*}{$\begin{array}{l}\text { Initial dispersion of } \\
\text { sediments }\end{array}$} & $\begin{array}{l}\text { Samples placed in } 50 \mathrm{ml} \text { plastic tubes, tubes filled with } 45 \mathrm{ml} \text { of } 5 \% \text { sodium } \\
\text { hexametaphosphate solution. Tubes shaken every half hour during } 24 \text { hours plus } 24 \text { hours } \\
\text { resting. Centrifuged } 1 \text { time at } 1500 \mathrm{rpm} \text { for } 3 \mathrm{~min} \text {, then supernatant removed with pipette }\end{array}$ & $\mathrm{X}$ & $x$ & & \\
\hline & $\begin{array}{l}\text { Samples placed in } 50 \mathrm{ml} \text { plastic tubes, tubes filled with } 45 \mathrm{ml} \text { of } 5 \% \text { sodium } \\
\text { hexametaphosphate solution. Tubes placed in ultrasound bath at } 60^{\circ} \mathrm{C} \text { for } 10 \mathrm{~min} \text {, } \\
\text { centrifuged at } 1500 \mathrm{rpm} \text { for } 3 \mathrm{~min} \text {, then supernatant removed with pipette (repeated twice) }\end{array}$ & & & $\mathrm{x}$ & $\mathrm{x}$ \\
\hline Rinsing & $\begin{array}{l}\text { Sample tubes filled with distilled water and centrifuged at } 2500 \text { rpm for } 2 \text { min, supernatant } \\
\text { removed with pipette (repeated } 3 \text { times) }\end{array}$ & $\mathrm{X}$ & $\mathrm{X}$ & $\mathrm{x}$ & $\mathrm{X}$ \\
\hline $\begin{array}{l}\text { Remove } \\
\text { carbonates }\end{array}$ & $\begin{array}{l}\text { Samples placed in } 50 \mathrm{ml} \text { plastic tubes, } 10 \% \mathrm{HCl} \text { added to the sample. Additional } 10 \% \mathrm{HCl} \\
\text { added until no further reaction is observed after shaking. Samples rinsed } 4 \text { times at } 2500 \\
\text { rpm for } 2 \mathrm{~min}\end{array}$ & $\mathrm{X}$ & $\mathrm{x}$ & $\mathrm{X}$ & $\mathrm{X}$ \\
\hline $\begin{array}{l}\text { Remove large } \\
\text { particles }\end{array}$ & Samples sieved with a $250-$ micron mesh & $\mathrm{X}$ & $\mathrm{x}$ & $\mathrm{x}$ & $\mathrm{x}$ \\
\hline Drying/weighing & Samples and large particles dried in oven at $90^{\circ} \mathrm{C}$, then weighed & $\mathrm{X}$ & $\mathrm{X}$ & $\mathrm{X}$ & $\mathrm{X}$ \\
\hline \multicolumn{6}{|l|}{ Phase 2} \\
\hline & Samples divided into 4 sub-samples & & & & \\
\hline \multirow{3}{*}{$\begin{array}{l}\text { Remove organic } \\
\text { matter }\end{array}$} & Sub-samples placed in crucibles and heated in oven at $550^{\circ} \mathrm{C}$ for 2 hours & $\mathrm{X}$ & & $\mathrm{X}$ & \\
\hline & $\begin{array}{l}\text { Sub-samples in plastic tubes, added } 20 \mathrm{ml} \text { of } 30 \% \mathrm{H}_{2} \mathrm{O}_{2} \text {, tubes placed in water bath at } 60^{\circ} \mathrm{C} \text {. } \\
\text { Once reaction slowed down, tubes centrifuged at } 2500 \mathrm{rpm} \text { for } 2 \mathrm{~min} \text {, added new } 30 \% \mathrm{H}_{2} \mathrm{O}_{2} \\
\text { and waited till no reaction is observed. Sub-samples rinsed } 4 \text { times at } 2500 \mathrm{rpm} \text { for } 2 \mathrm{~min}\end{array}$ & & $\mathrm{X}$ & & \\
\hline & $\begin{array}{l}\text { Sub-samples in plastic tubes, added } 20 \mathrm{ml} 30 \% \mathrm{H}_{2} \mathrm{O}_{2} \text {, tubes placed in ultrasound bath at } \\
60^{\circ} \mathrm{C} \text {. Cycles of } 30 \mathrm{~min} \text { ultrasound "On" and } 30 \mathrm{~min} \text { ultrasound "Off" are repeated until no } \\
\text { reaction is observed with ultrasound "Off". Sub-samples rinsed } 4 \text { times at } 2500 \text { rpm for } 2 \\
\text { min }\end{array}$ & & & & $\mathrm{x}$ \\
\hline \multirow[t]{2}{*}{ Remove clay } & $\begin{array}{l}\text { Sub-samples placed in } 50 \mathrm{ml} \text { plastic tubes, tubes filled with } 45 \mathrm{ml} \text { of } 5 \% \text { sodium } \\
\text { hexametaphosphate solution. Tubes vortexed and centrifuged at } 1500 \mathrm{rpm} \text { for } 3 \mathrm{~min} \text {, then } \\
\text { supernatant removed with pipette. Process repeated until supernatant is clear*. Sub- } \\
\text { samples rinsed } 4 \text { times at } 2500 \mathrm{rpm} \text { for } 2 \mathrm{~min}\end{array}$ & $\mathrm{x}$ & $\mathrm{X}$ & & \\
\hline & $\begin{array}{l}\text { Sub-samples placed in } 50 \mathrm{ml} \text { plastic tubes, tubes filled with } 45 \mathrm{ml} \text { of } 5 \% \text { sodium } \\
\text { hexametaphosphate solution. Tubes placed in ultrasound bath at } 60^{\circ} \mathrm{C} \text { for } 10 \mathrm{~min} \text {, } \\
\text { centrifuged at } 1500 \mathrm{rpm} \text { for } 3 \mathrm{~min} \text {, then supernatant removed with pipette. Process } \\
\text { repeated until supernatant is clear. Sub-samples rinsed } 4 \text { times at } 2500 \mathrm{rpm} \text { for } 2 \mathrm{~min}\end{array}$ & & & $\mathrm{X}$ & $\mathrm{x}$ \\
\hline Drying/weighing & Sub-samples dried in oven at $90^{\circ} \mathrm{C}$, then weighed & $\mathrm{X}$ & $\mathrm{X}$ & $\mathrm{X}$ & $\mathrm{X}$ \\
\hline \multicolumn{6}{|l|}{ Phase 3} \\
\hline \multirow[t]{2}{*}{ Flotation } & $\begin{array}{l}\text { Sub-samples placed in } 50 \mathrm{ml} \text { plastic tubes, added } 15 \mathrm{ml} \text { of SPT at } 2.3 \text { specific gravity. Tubes } \\
\text { centrifuged at } 3000 \mathrm{rpm} \text { for } 5 \mathrm{~min} \text {. } 10 \mathrm{ml} \text { of SPT with floating fraction moved to a second } \\
\text { tube. Repeated twice. Second tube filled with water, centrifuged at } 3000 \mathrm{rpm} \text { for } 10 \mathrm{~min} \text {, } \\
\text { diluted SPT recovered with pipette. Sub-samples rinsed } 4 \text { times at } 2500 \mathrm{rpm} \text { for } 2 \mathrm{~min}\end{array}$ & $\mathrm{X}$ & $\mathrm{X}$ & & \\
\hline & Same as above, but tubes placed in ultrasound bath for $10 \mathrm{~min}$ before floating & & & $\mathrm{X}$ & $\mathrm{X}$ \\
\hline Drying/weighing & Extracted phytoliths moved to glass vials, dried in oven at $90^{\circ} \mathrm{C}$, then weighed & $\mathrm{X}$ & $\mathrm{X}$ & $\mathrm{X}$ & $\mathrm{X}$ \\
\hline
\end{tabular}

